\title{
Glycemic Status of Type 2 Diabetic Subjects On Different Anti-Diabetic Management
}

\author{
Samdani TS ${ }^{\mathrm{a}}$, Rahim MA ${ }^{\mathrm{b}}$, Mitra Pc ${ }^{\mathrm{c}}$ Ahmed AKMS ${ }^{\mathrm{d}}$, Uddin $\mathrm{KN}^{\mathrm{c}}$
}

\begin{abstract}
:
Background: Diabetes mellitus (DM) is a complex multi-system disorder that may lead to diabetes specific complications and target organ damage which can be prevented or delayed by good or strict glycemic control. Our aims were to evaluate the glycemic status of adult type 2 DM (T2DM) patients on different anti-diabetic management, to evaluate role of education and economic status on glycemic control and to correlate glycemic status with complications.
\end{abstract}

Methods: This cross-sectional study was conducted in BIRDEM General Hospital from November 2013 to April 2015. Data were collected in a pre-formed data collection form, purposively and consecutively from 300 T2DM patients who were diagnosed as diabetic for 3 months or more and were compliant, after face to face interview and undergoing the required physical examinations. Then data were compiled and analyzed accordingly.

Result: Neither the educational level nor the monthly income had any influence on glycemic control. Only 17\% of the patients had good glycemic control $(\mathrm{HbAlc}<7)$ in spite of different anti-DM managements. The overall mean $\mathrm{HbAl}_{C}$ was $8.9 \pm 1.9 \%$, among which the group of patients with medical nutrition therapy had the lowest

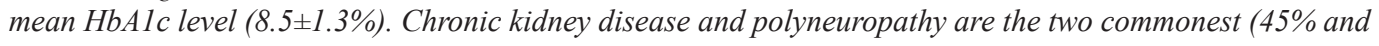
$40 \%$ respectively) complications with a significant $(r=1, p=0.000)$ positive correlation between both macro and microvascular complications of DM with uncontrolled glycemic status.

Conclusion: From the current study it can be concluded that glycemic control is rarely achieved and no treatment regimen is superior to other in achieving glycemic control. Patients educational or income level did not have any influence in glycemic control and there is a strong positive correlation between uncontrolled T2DM and it's complications.

Key words: Anti-diabetic management, complications of diabetes, glycemic status, type 2 diabetes mellitus.

(BIRDEM Med J 2017; 7(2): 121-126)

Author Information

a. Dr. Tasrina Shamnaz Samdani, Assistant Professor, Medicine, Delta Medical College and Hospital, Dhaka, Bangladesh

b. Dr. Muhammad Abdur Rahim, Assistant Professor, Nephrology and Dialysis, BIRDEM General Hospital, Dhaka, Bangladesh

c. Dr. Palash Mitra, Assistant Registrar, Nephrology and Dialysis, BIRDEM General Hospital, Dhaka, Bangladesh

d. Dr. A.K.M. Shaheen Ahmed, Associate Professor, Internal Medicine, BIRDEM General Hospital, Dhaka, Bangladesh

e. Prof. Khwaja Nazim Uddin, Professor, Internal Medicine, BIRDEM General Hospital, Dhaka, Bangladesh

Address of correspondence: Dr. Tasrina Shamnaz Samdani, Assistant Professor, Medicine, Delta Medical College and Hospital, Dhaka, Bangladesh. Email: tasrina20@gmail.com

Received: October 28, 2016

Accepted: February 28, 2017

\section{Introduction}

The prevalence of diabetes mellitus (DM) is increasing. Globally 347 million people are suffering from DM. ${ }^{1}$ WHO projects that diabetes will be the 7th leading cause of death in $2030 .^{2}$ Ninety percent of total diabetic patients are having type 2 diabetes mellitus (T2DM). ${ }^{3}$ Starting with the discovery of insulin in 1921, a long list of therapeutic options are available for treating DM. It is now established that good glycemic control reduces or at least delays diabetes specific complications. ${ }^{4,5}$ Targets of glycemic controls are advocated by different authorities. ${ }^{6,7}$ Most T2DM patients can be treated at outpatient (OPD) visits but glycemic targets are reached in up to one-third of cases. ${ }^{8-10}$ Some of the rest two-third of cases requires hospitalization at some point and 
necessitate readjustment of the dose of anti-diabetic drugs or institute a new drug. This study is designed to evaluate the glycemic status of adult T2DM patients at tertiary care settings at the time of hospitalization.

By the WHO, DM is considered as epidemic which is strongly related to lifestyle and economic changes. Diabetes magnifies the risk of vascular diseases several fold and is thus one of the major causes of morbidity and mortality worldwide. The availability of wide range of oral and injectable anti diabetic drugs gave us the hope of preventing complications of diabetes by achieving good glycemic control. This study will help us to understand the effect of different anti-diabetic drugs on glycemic status in study population which can be a guide for us to choose appropriate anti-diabetic $\operatorname{drug}(\mathrm{s})$ for good glycemic control of our patients and thereby lessen the burden of morbidity and mortality related to diabetes.

Our objectives were to evaluate the glycemic status of adult T2DM subjects at admission, to compare glycemic status of T2DM patients on different anti-diabetic medications, to evaluate the role of occupation, education and economic status on glycemic control and to correlate glycemic status with complications during admission at hospital.

\section{Methods}

\section{Study Design}

This cross-sectional observational study with descriptive and analytical component was undertaken in Department of Internal Medicine of BIRDEM General Hospital from November 2013 to April 2014. Data were collected in a preformed data collection form, from consecutive three hundred patients with type 2 diabetes mellitus who got admitted within the study period.

The adult non-pregnant T2DM subjects on regular antidiabetic medications with duration of T2DM for three months or more were included. But the newly detected T2DM patients (duration of disease less than three months), type $1 \mathrm{DM}$ and gestational diabetes mellitus (GDM) and other specific type of diabetes and noncompliant patients were excluded.

\section{Operational Definitions:}

DM:The current WHO diagnostic criteria for diabetes-

- $\quad$ Fasting blood glucose $\geq 7.0 \mathrm{mmol} / 1$

- 2-hours after ingestion of 75 gm glucose

$$
\geq 11.1 \mathrm{mmol} / 1^{7}
$$

Glycemic control:Targets are-

- Fasting blood glucose: Â $6.0 \mathrm{mmol} / \mathrm{L}$

- $\quad \mathrm{HbA} 1_{\mathrm{c}}: \hat{\mathrm{A}} 7.0 \%$

- 2-hour postprandial blood glucose: Â $8.0 \mathrm{mmol} / \mathrm{L}^{7}$

Compliant patients: Diabetic patients strictly adherent to prescribed medication at least for last two follow up.

\section{Sampling Technique:}

As study population was limited, purposive sampling technique was adopted.

\section{Statistical Analysis}

After collection all the data were checked and edited. Then data were entered into computer with the help of software SPSS for windows programmed version 20. After frequency run, data were cleaned and frequencies were checked. Each respondent has been given as his own code and was entered separately. An analysis plan was developed keeping in view with the objectives of the study. Data have been analyzed with this software where there are frequency table of the variables with mean, median standard deviation.

\section{Ethical Considerations}

Informed written consent was taken from all patients/ guardians regarding storage of medical data and possible use for scientific research without disclosing their identity. In this study no intervention was planned and identity of the recipients was not disclosed.

\section{Results}

Study population consisted of three hundred patients who were at regular follow up prior to hospitalization in internal medicine of BIRDEM General Hospital of whom $64 \%$ were female. Mean age of the patients were $54.79 \pm 10.28$ years [maximum patients are from 50 to 59 years of age $(111,37 \%)]$ with mean BMI $24.34 \pm$ 4.61 (table 1).

Table I. Base-line characteristics

\begin{tabular}{lc} 
Character & Value \\
\hline Age $($ mean \pm SD $)$ & $54.79 \pm 10.28$ \\
Male:Female & $108: 192$ \\
Weight $(\mathrm{kg})[$ mean $\pm \mathrm{SD}]$ & $59.59 \pm 12.43$ \\
Height $(\mathrm{cm})[$ mean $\pm \mathrm{SD}]$ & $155.44 \pm 8.49$ \\
BMI $\left(\mathrm{kg} / \mathrm{m}^{2}\right)[$ mean $\pm \mathrm{SD}]$ & $24.34 \pm 4.61$ \\
\hline
\end{tabular}

The mean $\mathrm{HbAl}_{\mathrm{c}}$ of these patients was $8.9 \pm 1.9 \%$, reflecting poor glycemic control and explains presence of both macro- and micro-vascular complication during hospitalization (table 2, 3, 4). Commonest co-morbidity 
was hypertension (HTN) and commonest complication of DM was chronic kidney disease (CKD) (table 4). In general, the glycemic control was poor in every age group, still patients aging 30 to 39 years showed relatively good control $\left(\mathrm{HbAl}_{\mathrm{C}}\right.$ was $<7 \%$ in $44 \%$ of patients of this age group) (table II).

Table II. HbA1c of different age group

\begin{tabular}{lccc}
$\begin{array}{l}\text { Age group } \\
\text { years) }\end{array}$ & $\begin{array}{c}\text { No, of } \\
\text { patients } \\
{[\mathrm{n}(\%)]}\end{array}$ & $\begin{array}{c}\text { HbAlc } \\
<7 \% \\
{[\mathrm{n}(\%)]}\end{array}$ & $\begin{array}{c}\text { HbAlc } \\
\geq 7 \% \\
{[\mathrm{n}(\%)]}\end{array}$ \\
\hline$<30$ & $6(2 \%)$ & $2(33 \%)$ & $4(67 \%)$ \\
$30-39$ & $9(3 \%)$ & $4(44 \%)$ & $5(56 \%)$ \\
$40-49$ & $63(21 \%)$ & $12(19 \%)$ & $51(81 \%)$ \\
$50-59$ & $111(37 \%)$ & $9(8 \%)$ & $102(92 \%)$ \\
$60-69$ & $87(29 \%)$ & $21(24 \%)$ & $66(76 \%)$ \\
$\geq 70$ & $24(8 \%)$ & $3(12 \%)$ & $21(88 \%)$ \\
\hline
\end{tabular}

Fasting blood glucose (FBG), post prandial blood glucose (PPBG) of after breakfast (ABF), after launch $(\mathrm{AL})$, after dinner (AD) all were way beyond the target value in these patients (table III)

Only $18(6 \%)$ patients were on diabetic diet only and most of the patients $(195,65 \%)$ were on insulin. Glycemic control was found to be inadequate in all the patients whichever the treatment is (table V).

Among our three hundred patients, most of them had educational background of secondary or higher secondary level with monthly income of 10,000 to 30,000 taka. Satisfactory glycemic control was found more in uneducated study population and persons with least income group (table VI - VII).

All the macro- and micro-vascular complications in our study population was common after 15 years of DM except cerebro-vascular disease, which was evident in patients with DM of less than 10 years. Incidence of these the complications were less in patients with good glycemic control. (table VIII)

Table III. Glycaemic status

\begin{tabular}{llcc} 
& & Frequency & Percent \\
\hline HbA1c \% & Mean & $8.9 \pm 1.9$ & \\
& $<7$ & 51 & 17 \\
& $7-8.5$ & 137 & 46 \\
& $>8.5$ & 112 & 37 \\
FBG (m.mol/L) & Mean & $10.37 \pm 4.2$ & \\
& $<6.0$ & 27 & 9 \\
PPBG (m.mol/L) ABF & Mean & $13.43 \pm 4.4$ & \\
& $<8.0$ & 30 & 10 \\
& $\geq 8.0$ & 270 & 90 \\
PPBG (m.mol/L) AL & Mean & $13.77 \pm 5.2$ & \\
& $<8.0$ & 33 & 11 \\
& $\geq 8.0$ & 227 & 89 \\
PPBG (m.mol/L) AD & Mean & $12.24 \pm 5.1$ & \\
& $<8.0$ & 51 & 17 \\
& $\geq 8.0$ & 249 & 83 \\
\hline
\end{tabular}

Table IV. Co-morbidities and complications of DM during hospitalization

\begin{tabular}{lcc} 
Co-morbidities & Frequency & Percent \\
\hline Hypertension & 255 & 85 \\
Ischaemic heart disease & 81 & 27 \\
Chronic kidney disease & 135 & 45 \\
Non-alcoholic fatty liver disease & 0 & 0 \\
Dyslipidaemia & 102 & 34 \\
Stroke & 21 & 7 \\
Hypothyroidism & 36 & 12 \\
\hline
\end{tabular}

Table V. Glycaemic status of patients on different anti-diabetic management

\begin{tabular}{lccccc}
$\begin{array}{l}\text { Anti-diabetic } \\
\text { management }\end{array}$ & $\begin{array}{c}\text { Frequency, } \\
\text { percent }\end{array}$ & $\begin{array}{c}\text { Mean } \\
\text { BMI }\end{array}$ & $\begin{array}{c}\text { Mean } \\
\text { HbA1c }(\%)\end{array}$ & $\begin{array}{c}\text { Mean FBG } \\
(\mathrm{m} . \mathrm{mol} / \mathrm{L})\end{array}$ & $\begin{array}{c}\text { Mean PPBG } \\
(\mathrm{m} . \mathrm{mol} / \mathrm{L})\end{array}$ \\
\hline Diet & $18(6 \%)$ & $23.8 \pm 3.1$ & $8.5 \pm 1.3$ & $9.9 \pm 3.3$ & $12.3 \pm 3.8$ \\
Oral drugs & $30(10 \%)$ & $24.1 \pm 4.6$ & $8.8 \pm 2.3$ & $9.3 \pm 2.7$ & $12.9 \pm 3.4$ \\
Insulin & $195(65 \%)$ & $24.0 \pm 4.2$ & $8.8 \pm 2.0$ & $10.6 \pm 4.5$ & $13.4 \pm 4.8$ \\
Combinations & $57(19 \%)$ & $26.0 \pm 5.9$ & $9.2 \pm 1.5$ & $10.2 \pm 3.6$ & $14.2 \pm 3.6$ \\
\hline
\end{tabular}


Table VI. Status of glycemic control in patients from different educational background

\begin{tabular}{lccc} 
Education & $\begin{array}{c}\text { Total patient(pt) } \\
\mathrm{n}(\%)\end{array}$ & $\begin{array}{c}\text { No of pt with } \\
\text { HbAlc }<7 \mathrm{n}(\%)\end{array}$ & $\begin{array}{c}\text { No of pt with } \\
\text { HbAlc } \geq 7 \mathrm{n}(\%)\end{array}$ \\
\hline None & $36(12 \%)$ & $15(42 \%)$ & $21(58 \%)$ \\
Primary & $45(15 \%)$ & $3(7 \%)$ & $42(93 \%)$ \\
Secondary & $84(28 \%)$ & $15(18 \%)$ & $69(82 \%)$ \\
Higher Secondary & $84(28 \%)$ & $12(14 \%)$ & $72(86 \%)$ \\
Graduate & $45(15 \%)$ & $6(13 \%)$ & $39(87 \%)$ \\
Post graduate & $6(2 \%)$ & $0(0 \%)$ & $6(100 \%)$ \\
\hline
\end{tabular}

Table VIII. Status of glycemic control in patients from different income group

\begin{tabular}{lccc} 
Income range & $\begin{array}{c}\text { Total patient } \\
\mathrm{n}(\%)\end{array}$ & $\begin{array}{c}\text { No of pt with } \\
\text { HbAlc }<7 \mathrm{n}(\%)\end{array}$ & $\begin{array}{c}\text { No of pt with } \\
\text { HbAlc } \geq 7 \mathrm{n}(\%)\end{array}$ \\
\hline$<10,000 /$ month & $84(28 \%)$ & $30(36 \%)$ & $54(64 \%)$ \\
10,000 to $<30,000 /$ month & $138(46 \%)$ & $21(15 \%)$ & $117(85 \%)$ \\
30,000 to $<50,000 /$ month & $45(15 \%)$ & $0(0 \%)$ & $45(100 \%)$ \\
$>50,000 /$ month & $33(11 \%)$ & $0(0 \%)$ & $33(100 \%)$ \\
\hline
\end{tabular}

Table IX. Relationship of complication during admission at hospital with mean duration of DM and glycemic control.

\begin{tabular}{|c|c|c|c|c|}
\hline Complications & $\begin{array}{c}\text { Number of } \\
\text { patients }\end{array}$ & $\begin{array}{l}\text { Mean duration } \\
\text { of DM (years) }\end{array}$ & $\begin{array}{c}\text { No. of patients with } \\
\text { HbAlc }<7 \%\end{array}$ & $\begin{array}{c}\text { No. of patients } \\
\text { with } \mathrm{HbA} 1 \mathrm{c} \geq 7 \%\end{array}$ \\
\hline Ishcaemic heart desease & 81 & $15.49 \pm 10.09$ & 6 & 75 \\
\hline Chronic kidney disease & 135 & $15.18 \pm 8.24$ & 24 & 111 \\
\hline Cerebrovascular disease & 21 & $7.73 \pm 3.87$ & 3 & 18 \\
\hline Diabetic retinopathy & 120 & $15.35 \pm 8.21$ & 12 & 108 \\
\hline Diabetic polyneuropathy & 81 & $16.11 \pm 9.66$ & 12 & 69 \\
\hline Peripheral vascular disease & 9 & $17.26 \pm 6.27$ & 3 & 6 \\
\hline
\end{tabular}

* significant $(\mathrm{r}=1, \mathrm{p}=0.000)$ positive correlation between both macro and microvascular complications of DM with uncontrolled glycemic status.

\section{Discussion}

Diabetes mellitus is a leading cause of death and disability worldwide. Its global prevalence was about $8 \%$ in 2011 and is predicted to rise to $10 \%$ by 2030 . Nearly $80 \%$ of people with diabetes live in low- and middle-income countries. Asia and the eastern Pacific region are particularly affected: in 2011, China was home to the largest number of adults with diabetes (i.e. 90.0 million, or $9 \%$ of the population), followed by India
(61.3 million, or $8 \%$ of the population) and Bangladesh (8.4 million, or $10 \%$ of the population). ${ }^{11}$ Globally $60 \%$ of the people with DM are of Asian descendant. $40 \%$ of all people with diabetes in least developed countries live in Bangladesh. ${ }^{12}$ Only $7.8 \%$ of people with diabetes in Bangladesh can achieve the target. ${ }^{13}$

In this study these relatively well glycemic control was found in illiterate and low income society' patients. On 
the other hand in a few highly educated and representative of high society population group reflects relatively poor control of DM, which can be explained by their uncontrolled dietary habit and sedentary lifestyle.

Associations with glycemic control with educational level and socioeconomic status vary internationally. The associations found in this study, between these two factors and diabetes have also been observed previously in Bangladesh, China and India. In contrast, another study in China found that the prevalence of diabetes was generally unaffected by educational level but was higher in the high-income group. Moreover, studies from both developing and developed countries have found inverse associations between diabetes and educational level and household socioeconomic status. ${ }^{14}$

It's a fact that having high blood glucose levels over a long period of time will cause damage to the large blood vessels in heart, brain and feet and smaller blood vessels supplying eyes, kidneys and nerves. Prolong uncontrolled DM had led to various macro- and microvascular complications in my study population. However, it is important to maintain a healthy blood pressure and cholesterol level to reduce existing risk of complications.

In a study on more than 8000 Bangladeshi population, Akhter $\mathrm{S}$ et al had pointed out the following barriers of good outcome in DM control ${ }^{11}$.

- The unavailability of health insurance, except in small areas of the country where it is provided by programs run by nongovernmental organizations

- Inadequately trained staff and limited health-care facilities in rural areas

- Rapid lifestyle changes caused by urbanization

- The absence of health awareness programs in the education curriculum.

This study was done only in 300 hospitalized populations. This can give an insight of the current status and response to management of antidiabetic management with burden of complications in patients from various age group, socio-economic and educational background in our country.

In conclusion, good glycemic control is the sole way to keep a diabetic person healthy and avoid the disabling and life threatening complications. To achieve this, our target should be to overcome the following barriers of good glycemic control -

- Lack of education and awareness about diabetes, its complications and its cost

- Lack of high-quality health care professionals and clinics, long distance to facilities and long waiting time for treatment

- It is difficult for many people with diabetes to remember medication and follow scheduling, many have a fear of injections, and many are stigmatized and have psychological issues

- Many cannot afford medicine and treatment services, the majority do not have health insurance or access to other finance solutions, and the healthcare system is lacking the necessary resources to treat diabetes

- Some medicines/package solutions are not available in the country or in the region

Declaration: This paper was presented in the 33rd World Congress of Internal Medicine, Bali, Indonesia, 2016.

\section{References}

1. Danaei G, Finucane MM, Lu Y, Singh GM, Cowan MJ, Paciorek CJ et al. National, regional, and global trends in fasting plasma glucose and diabetes prevalence since 1980: systematic analysis of health examination surveys and epidemiological studies with 370 country-years and 2.7 million participants. Lancet, 2011; 378(9785):31-40.

2. Global status report on noncommunicable diseases 2010. Geneva, World Health Organization, 2011.

3. Definition, diagnosis and classification of diabetes mellitus and its complications. Part 1: Diagnosis and classification of diabetes mellitus. Geneva, World Health Organization, 1999 (WHO/NCD/NCS/99.2).

4. DCCT (The Diabetes Control and Clinical Trial) Research Group. The effects of intensive treatment of diabetes on the development and progression of long-term complications in insulin-dependent diabetes mellitus. N Eng J Med 1993;329:977-86

5. UKPDS (UK Prospective Diabetes Study) Group. Intensive blood-glucose control with sulphonylureas or insulin compared with conventional treatment and risk of complications in patient with type 2 diabetes: UKPDS 33. Lancet 1998; 352: 837-53.

6. Clinical Practice Recommendation 2010, American Diabetes Association. 
7. International Diabetes Federation 2012 Clinical Guideline Taskforce, Global Guideline for Type 2 Diabetes.p.38.

8. Latif ZA, Jain A, Rahman MM. Evaluation of management, control, complication and psychological aspect of diabetics in Bangladesh. DiabCare Bangladesh 2008. Bangladesh Med Res Coun Bull 2011; 37(1):11-16.

9. Chua SS, Chan SP. Medication adherence and achievement of glycemic targets in ambulatory type 2 diabetic patients. J Applied Pharm Sci 2011; 1(4): 55-59.

10. Eid M, Mahfuzy M, Faridah AR. Glycemic control of type 2 diabetic patients on follow up at Hospital Universiti
SainsMalayasia. Malayasian J Med Sci 2003; 10(1): 40-49.

11. Akter S, Rahman MM, Abe SK, Sultana P. Prevalence of diabetes and prediabetes and their risk factors among Bangladeshi adults: a nationwide survey. Bulletin of the World Health Organization 2014;92:204-213A.

12. Bhowmik B, Afsana F, Diep LM, Munir SB, Wright E, Mahmood S et al. Increasing Prevalence of Type 2 Diabetes in a Rural Bangladeshi Population: A Population Based Study for 10 Years. Diabetes Metab J 2013;37:46-53.

13. The Blueprint for Change Programme June 2012. 